\title{
On the Functional-Communicative Aspect of Literary Texts
}

\author{
Mariana Sargsyan \\ Yerevan State University
}

\begin{abstract}
$\mathrm{T}$ he problem whether the literary text should be regarded within the frames of functional stylistic system remains disputable. Some scholars insist that literary texts should by no means be regarded as one of the manifestations of functional styles, still others argue this point in their consideration on the problem coming from the premise that the language of a literary text is endowed with functional specificities. Therefore, both parties regard the literary text as possessing a complex nature and, consequently, refer literary texts to a higher order (Valgina 2003).
\end{abstract}

Nowadays, a vast number of investigations favor the opinion that verbal art (literary art) is and should be considered an indispensable unit of the functional stylistic system of the language. Moreover, literary texts obtain their overall definition when the study of functional aspects thereof comes to interfere.

Any piece of literary art is the result of the author's unique and creative speech activity: therefore, the text encompasses a wide range of cognitive and psychological features inherent to a certain author.

An increasingly large number of investigations in the field of literary art lead us to the belief that texts are not created for mere enjoyment; neither are they meant for simply informing the reader. Literary texts are endowed with the unique peculiarity, i.e. sharing with the reader the author's world outlook and attitude toward the realia of the external life. It is due to presentation and evaluation that the author delivers his message to the reader. Texts serve as a means through which the author intends to generate a specific aesthetic impact on the reader and bring forth a certain psychological state, thus making the reader live and experience through the thoughts and feelings of the author.

As can be concluded from the aforementioned, the literary text functions as a means of establishing a kind of communication between its creator and receiver. Having this in mind, linguists define the literary text as a two-fold phenomenon. For one thing, the literary text is the result of the author's creative speech activity. For the other, it is a readymade material meant for the reader's understanding and interpretation (Valgina 2003).

Manifestations of individuality are materialized in the author's individual style which is presented in the form of generalizations. The literary text provides an objective, national and cultural specific viewpoint, filtered through the prism of the creator's subjective attitude. The latter comes into being, materializes through images which serve as a code for generalizations. The images come forth when text components employed by the author become charged by expressive-emotive-evaluative overtones imposed on them on the part of the creator.

The aforementioned does not aim at arguing the point that the literary text has a meaning of its own. We aim at clearly stating that it is not the words that create the meaning of the text. Just the contrary, the meaning of the text is realized through the expres- 
sive-emotive-evaluative overtones imposed on the words. Thus, the function of the words within the literary text is not confined to mere denotation. Words realize all their connotative potential meanings and sometimes obtain new ones not inherent to them in customary situations.

Thus, the words function according to the author's skillful intention and serve the whole ideology of the text to establish a communicative bridge with the reader. The fact that the components of the text are carefully selected by the author with the aim of influencing the reader and that their role is confined to serving the ideological completeness of the text can hardly be ignored.

It is in this sphere that the functional analysis comes to play a decisive role. The functional approach to any kind of text, particularly a literary one, is a main clue which helps to reveal the authentic content (content proper) of the text and expose how text components function as a communicative unit for delivering the author's message, as well as introducing his ideological intention.

Indisputable remains the fact that linguistic signs grow more concrete and precise when the close contact between the signs of different layers is taken into consideration. It is under the influence of the context that elements realize the whole range of their potentialities.

So, how does functional approach contribute to the study of literary texts? The answer can be roughly reduced to the following points:

1. First and foremost, functional analysis enables to break the frames of pure linguistic and stylistic aspects of the study of literary texts and reach the analysis of such conceptual categories like literary time and space, the author's intention, ideological standpoint, as well as the whole range of cultural and historical data underlying the whole ideology of the text.

2. Further, functional analysis helps to explore the ways the linguistic units correlate with the ideology of the text. There is no doubt that in literary texts words develop a panorama of such meanings which are typical of the given specific content.

3. Last, but not least, functional analysis helps to establish ties with various texts, thus enabling a versatile analysis to contribute to the revelation of the whole meaning and real value of texts written not only by a certain author but different authors at a time.

It logically follows from what has been said above that the functional analysis identifies how the text functions as a communicative unit of speech, on the other hand demonstrating the ways the text components work in favor of maintaining a successful communicative act, thus enabling the reader to disclose the whole range of data encompassed therein. This entails enhancing the reader's cultural awareness.

In the present paper our analysis is aimed at revealing how the words function within the context of a literary text in favor of disclosing the author's intention from the perspective of representing cultural information. In our analysis we come from the premise that words and images employed by the author express, embody and to some extent symbolize the cultural reality.

Let's demonstrate the aforementioned through the following example: 
The feature of the feast was read mullet. This delectable fish brought

from a considerable distance in a state of almost perfect preservation was first fried, then boned, then served in ice according to a recipe known to a few men of the world.

(J. Galsworthy)

The adduced passage is extracted from J. Galsworthy's resounded trilogy "The Forsyte Saga". The basic idea of the novel develops round the lifestyle of the bourgeois society of the Victorian Era, which is combined with the author's satirical, at times sympathetic criticism of the hollow insularity of everything from matters of property, marriage and even to food. Everything in the lifestyle of the family is associated with luxury and high style. The Forsyte obsession with wealth, status and acquisition is apparent, and the members of the family themselves are keenly aware of their position. J. Galsworthy delves into the description of every aspect of their whimsy lifestyle including the process of taking food.

It is interesting to note that in the passage the image created by the adjectives delectable, perfect and the word combinations brought from a considerable distance and known to a few men of the world become overloaded by the main ideology of the text consisting in outlining the whole exuberance and luxury of a society into which the author was born himself. People who identify themselves as members of a certain social group acquire common ways of viewing the world. Common attitudes, beliefs and values are reflected in the way the members of the group use language, i.e. what they choose to say or not say, and how to say it. Thus, in the above mentioned passage we deal with a kind of discourse community sharing a similar attitude toward food. The food the representatives of the given community take is to be exquisite and made perfectly consistent with their whimsy palate.

For those who are unfamiliar with the ideology embedded in J.Galsworthy's work, the passage will sound quite usual and will fail to generate any correlation with the whole ideology of the text. The passage makes a part not only of the whole ideology but it stands as a kind of symbol of the cultural identity of people who share the same status of "money". Within the frames of the whole text and especially in the given passage, we witness the subtle criticism of the author which is flavored with sympathy for the society which was already dying out.

The linguistic units delectable, perfect, brought from a considerable distance, known to a few men of the world implicitly introduce the notions of luxury and enjoyment, things that could not be separated from the lifestyle of higher society thus contributing to both ideological and cultural functioning of the text.

To show that even at first sight stylistically neutral words can function under the influence of context, let us have a brief look at the following two passages:

Any working-class wife who has thin times will have a fine knowledge of those cuts which are inexpensive and nourishing and also tasty.

(R.Hoggart) 
"There's no bloody hear room", agreed Slogger, chewing pie with the noisy relish of a man whose missus usually gave him cut bread and dripping. But this was a bloody good pie.

\section{(A.J.Cronin)}

In the above mentioned passages, where exquisiteness and luxury are not mentioned, we deal with a different kind of discourse community. Moreover, in this passage food is an indicator of a low society where food is not a topic of a lengthy conversation. The comparison, or to put it precisely, the contrast of the two notions proves that on the functional level the passages play the same role. The disagreement between red mullet and cuts on the one hand, and delectable and tasty or perfect and inexpensive or nourishing on the other, sheds a good deal of light upon the fact to what extent text components can concentrate and materialize the author's ideological standpoint.

Thus, through the writer's artistic verbal expression the reader observes a comprehensive picture of cultural identity of people belonging to different layers of society. The means through which this identity is exposed are to some extent culture based and overloaded with the evaluative and emotive overtones. The usage of the mentioned linguistic units results in reproducing the atmosphere the author aims to depict.

To sum up, an adequate understanding of the literary text can be achieved by means of considering the interaction of the text units with the underlying ideology. From the functional perspective the careful consideration of every unit within the whole comes to prove the assertion that each unit of the text is intended to fill in the gap that exists between the author and the intended reader at the outset. Since the two parties of communication are separated by time and space, and consequently, by history and cultural divergences, the understanding becomes an intricate problem to be solved. Thus, the concentration of a wide range of information in the text units aims at enhancing the process of understanding and establishing a successful communicative act.

It may well be concluded that the understanding of literary texts can be achieved at the crossroads of works by authors of different genres. The contradiction of different texts helps in revealing the functional affinities that texts possess from the perspective of enhancing the reader's awareness.

\section{References:}

1. Back, D.P. (2001) Avtorskoe soznanie w literaturnom proizwedenii. Teoriya $i$ istoriya. M.: RGGU.

2. Kramsch, C. (2009) Language and Culture. Oxford: Oxford University Press.

3. Kamenskaya, O.L. (1990) Tekst $i$ communikatsiya. M.: Library.ru.

4. Ter-Minasova, S.G. (2000) Yazyk i mejkulturnaya kommunikaciya. M.: Slovo.

5. Valgina, N.S. (2003) Teoriya teksta. M.: Logos. 


\section{Literature:}

1. Galsworthy, J. (1976) The Forsyte Saga. (Trilogy). M.: Progress.

2. Cronin, A.J. (1931) Complete works. New York: Little Brown.

3. Hoggart, R. (1957) The Uses of Literacy. India: Penguin Books.

9-tпupцkuunulyufi uutinduqnpдnıpJufi

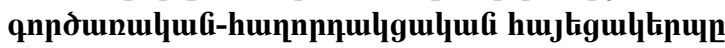

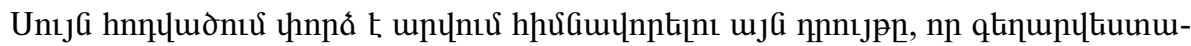

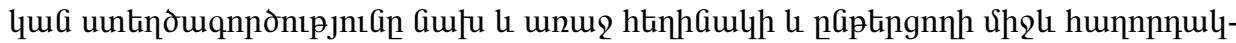

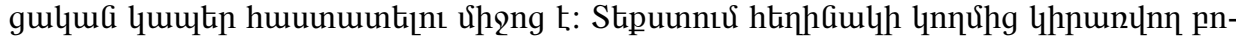

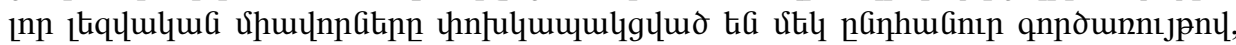

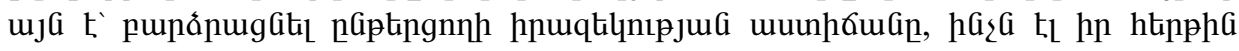

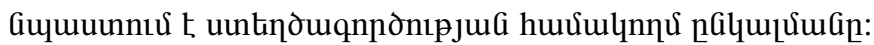

